\title{
Estado de portador de neumococo en niños y su relación con la enfermedad invasiva. ¿Qué ha cambiado tras la introducción de la vacuna conjugada?
}

\author{
C. García Vera \\ Pediatra. CS Sagasta-Ruiseñores. Zaragoza. \\ Investigador colaborador del Instituto Aragonés de Ciencias de la Salud.
}

\begin{abstract}
Resumen
En la última década se han sucedido cambios importantes relativos a la enfermedad neumocócica invasiva (ENI) en los países desarrollados. Con la generalización de la vacuna neumocócica conjugada heptavalente (VNC-7), se ha constatado la efectividad de la vacuna para disminuir la ENI por los serotipos incluidos en dicha vacuna (STV), pero también han surgido nuevos serotipos no incluidos y que han emergido con fuerza como productores de ENI. Afortunadamente, la carga de la enfermedad invasiva ahora provocada por los no vacunales en niños menores de cinco años es sensiblemente menor que la que provocaron los STV en la era prevacunal, y esta tendencia parece estable en el tiempo. Pero este proceso se ha seguido en paralelo por cambios similares en la colonización nasofaríngea por neumococos, muy frecuente en niños menores de cinco años, de manera que en la actualidad los STV han disminuido radicalmente en portadores sanos, y han sido sustituidos por no vacunales que terminan produciendo ENI. Este reemplazo de serotipos ha tenido también como consecuencia que las resistencias a antibióticos hayan descendido, ya que estas eran más prevalentes entre los STV. Recientemente se han comercializado dos nuevas vacunas conjugadas que amplían la protección a nuevos serotipos. Este artículo pretende repasar los cambios que se han producido y las expectativas e incertidumbres que se abren en esta nueva etapa de las vacunas neumocócicas conjugadas.
\end{abstract}

Palabras clave: Streptococcus pneumoniae. Colonización. La nasofaringe. Enfermedad neumocócica invasiva. Vacuna conjugada antineumocócica.

César García Vera: cgarciavera@gmail.com

Conflicto de intereses: el autor ha sido invitado por Laboratorios Pfizer, como asistente, a la ll y III Reunión de Expertos en Vacunación Antineumocócica Conjugada celebradas en Madrid en los años 2009 y 2010. Además fue becado por laboratorios GSK para la realización del Curso Universitario Experto en Vacunas de la Universidad Complutense de Madrid en 2008/9. 
The state of pneumococci asymptomatic carrier in children and its relation to the invasive disease. What has changed after the conjugated vaccine introduction?

\section{Abstract}

Some important changes relating to the pneumococcal invasive disease (PID) have happened in the last decade in developed countries. The effectiveness of the pneumococcal conjugate heptavalent vaccine (PCV-7) in diminishing the PID by the serotypes included (STV) has been proved after its generalization, but some new serotypes not included have aroused with force as cause of PID. Fortunately, the load of the disease by not included serotypes in children younger than five years is much lower than the caused by STV before the vaccine, and this tendency seems steady with time. But this process has followed parallel to similar changes in the nasopharyngeal colonization by pneumococci, very frequent in under five children, so that now STV have dramatically diminished in healthy carriers and have been substituted by non vaccine serotypes that end by causing PID. This serotypes' replacement have made the antibiotic resistances to diminish due to the fact that they were more prevalent among STV. Two new conjugated vaccines have been commercialized recently and they extend the protection to new serotypes. This paper reviews the changes, expectations and uncertainties that open this new stage in conjugated penumococcal vaccines.

Key words: Streptococcus pneumoniae. Colonization. Nasopharynx. Invasive pneumococcal disease. Pneumococcal conjugated vaccine.

\section{Introducción}

Streptococcus pneumoniae continúa siendo una de las causas más frecuentes de enfermedad invasiva bacteriana, particularmente en los dos polos de la vida humana (niños preescolares y ancianos). Conocemos hoy 92 familias (serotipos) de neumococos con potencial para producir patología en la especie humana, que se han ido clasificando en 46 serogrupos en función de las características de los polisacáridos capsulares. Los serogrupos se han ido numerando progresivamente, y se ha impuesto la nomenclatura danesa que dentro de cada grupo va denominando los diferentes serotipos el primero con la letra $\mathrm{F}$, y los sucesivos dentro de ese serogrupo consecutivamente con las letras A, B, C, etc. '.

Todas las enfermedades causadas por neumococo están precedidas de una colonización nasofaríngea asintomática de mayor o menor duración². La edad en que más frecuentemente se demuestra el estado de portador y la transmisión persona a persona va del mes de vida a los cinco años y se corresponde precisamente con la de mayor incidencia de la enfermedad neumocócica². Conviene recordar y resaltar que, a pesar de la importancia de la enfermedad neumocócica invasiva (ENI), el estado de portador tiene mucha mayor importancia para el entorno que para el pro- 
pio colonizado, debido a la potencial contagiosidad.

La morbilidad y la mortalidad asociadas a ENI son altas a nivel global, por lo que se ha considerado un problema de salud pública de actuación prioritaria. Se ha estimado que cada año mueren en el mundo 1,6 millones de personas (de ellas entre 700000 y un millón corresponderían a niños menores de cinco años) por infecciones neumocócicas, la gran mayoría en países en vías de desarrollo ${ }^{3}$. La incidencia de ENI en niños pequeños ( $<5$ años) en EE.UU. y Europa es de 8 a 75 casos anuales por 100000 niños de esa edad, mientras que en países en desarrollo se eleva hasta 100-500 casos anuales por $100000^{4,5}$. Además, en adultos y ancianos de países en vías de desarrollo, la mortalidad atribuida a la infección neumocócica es muy alta y en su mayor parte evitable ${ }^{6}$.

La drástica disminución como productores de ENI de los serotipos incluidos en la vacuna neumocócica conjugada 7-valente (VNC-7), tras su introducción en los países en los que se han logrado am- plias coberturas ${ }^{7-9}$, se ha correlacionado con un radical descenso de la presencia de estos serotipos también en la nasofaringe de niños sanos, vacunados o no. Se comprueba que el número total de niños portadores de neumococo permanece similar al del periodo prevacunal, pero nuevos serotipos (bien correlacionados en general con los emergentes como productores de ENI) han ocupado el lugar dejado por los vacunales. En nuestro país se han publicado datos contradictorios sobre la disminución global de la ENI en niños preescolares (que expondremos más adelante), pero donde no cabe discusión es en la disminución de ENI provocadas por los serotipos incluidos en la VNC-7 y en el reemplazo por los no vacunales. Los pocos estudios en portadores sanos ${ }^{10-12}$ también muestran la disminución brusca de los serotipos vacunales que ahora colonizan la nasofaringe de los niños preescolares sanos, y su sustitución por nuevas cepas emergentes, lo que mantiene el porcentaje de niños sanos preescolares porta-

Tabla 1. Vacunas neumocócicas conjugadas comercializadas en nuestro país

\begin{tabular}{|c|c|c|c|}
\hline Vacuna & Serotipos & Nombre comercial & Disponibilidad \\
\hline 7-valente & $4,6 \mathrm{~B}, 9 \mathrm{~V}, 14,18 \mathrm{C}, 19 \mathrm{~F}, 23 \mathrm{~F}$ & Prevenar $^{\circledR}$ (Pfizer) & Junio 2001 \\
\hline 10-valente & 7-valente más 1,5 y $7 \mathrm{~F}$ & Sinflorix ${ }^{\circledast}$ (GSK) & Agosto 2009 \\
\hline 13-valente & 10-valente más $3,6 \mathrm{~A}$ y $19 \mathrm{~A}$ & Prevenar13 ${ }^{\circledR}$ (Pfizer) & Junio 2010 \\
\hline
\end{tabular}


dores de neumococo en torno a un 30\%-35\% (detectados mediante hisopado nasofaríngeo y posterior cultivo según técnica estándar recomendada ${ }^{13}$ ).

Para responder a los cambios que se han producido en la etiología de la ENI ya se han comercializado dos nuevas vacunas (tabla 1) que amplían el número de serotipos en su formulación: decavalente (Synflorix ${ }^{\circledast}$, laboratorios CSK) y tridecavalente (Prevenar-13 ${ }^{\circledR}$, Pfizer).

Este artículo, en la línea de actualización abierta por una excelente revisión sobre el tema publicada en esta revis$\mathrm{ta}^{14}$, pretende, desde la perspectiva de la evolución de los serotipos en portadores y en la ENI, realizar un análisis de la situación heredada tras la era de la vacuna heptavalente, revisar las expectativas ante las nuevas vacunas deca- $y$ tridecavalente y poner de manifiesto, junto con los logros de la vacuna, las incertidumbres ante nuevos fenómenos de reemplazo.

\section{La condición de estado de portador de neumococo en la infancia. \\ Relación con la enfermedad invasiva}

Decíamos que está aceptado que toda enfermedad neumocócica en la infancia ha sido precedida por una colonización asintomática en la nasofaringe, colonización que puede ser más o me- nos duradera en función de diferentes factores, pero principalmente de la invasividad de cada serotipo, de la presión antibiótica y, más recientemente, de la vacunación VNC-7.

La distribución de los distintos serotipos en la nasofaringe varía poco según países o tipo de colectivo ${ }^{2,4}$. Entre Canadá, EE.UU. y la mayoría de los países europeos, apenas se constatan diferencias $y$, en la era prevacunal los principales serotipos en portadores eran los siguientes: 19F, 6B, 14, 23F, 6A. Sí se comprobaba que la presencia de serotipos incluidos en la vacuna disminuía con la edad, pues eran menos detectados en la nasofaringe a partir de los 6-8 años ${ }^{15}$, mientras que en edades posteriores, a partir de los 810 años y en adultos, aparecían como colonizadores serotipos menos detectados en edades precoces (serotipos 3, 8, 10, 11 y 15)

Con los resultados aportados por la investigación de Shouval ${ }^{16}$ queda clara la estrecha relación entre la presencia de los serotipos que colonizan la nasofaringe y los que provocan infección. Así, con datos obtenidos a partir de cuatro estudios en la era prevacunal, entre los nueve serotipos que más frecuentemente producían ENI (por orden de frecuencia serotipos 1, 5, 19F, 19A, 14, 23F, 6A, 6B y 9V), siete estaban entre los más frecuentemente 
encontrados en la nasofaringe $(6 \mathrm{~A}, 14$, $32 \mathrm{~F}, 19 \mathrm{~F}, 6 \mathrm{~B}, 19 \mathrm{~A}$ y $9 \mathrm{~V})$ de portadores sanos.

El "nicho ecológico" principal de $S$. pneumoniae es la nasofaringe de los niños, y se estima que prácticamente todos los niños en algún momento de su etapa preescolar han sido ya portadores de neumococo en al menos una ocasión ${ }^{17}$. La colonización nasofaríngea sucede a edades muy tempranas. La edad media de la primera colonización por neumococo son seis meses (e incluso antes en niños de países en desarrollo). Por tanto, teniendo en cuenta que la mayoría de los niños sanos han portado neumococo, muy pocos finalmente desarrollan enfermedad invasiva, por lo que deberíamos considerar esta como una complicación habitualmente rara. El problema, sobre todo, es que, aunque la mayoría de los niños no van a padecer enfermedad, sí van a ser los principales reservorios $y$ transmisores de la bacteria en el entorno.

S. pneumoniae es parte de la flora comensal del tracto respiratorio superior en conjunto con otras bacterias, entre las cuales las más reconocidas son MoraxeIla catarrhalis, Haemophilus influenzae, Neisseria meningitidis, Staphylococcus aureus y varios tipos de Streptococcus haemolyticus ${ }^{2}$. La colonización nasofaríngea es un proceso dinámico por el re- cambio constante de especies y serotipos colonizadores. Existe un equilibrio entre la flora autóctona y los gérmenes que transitoriamente la invaden, y es un equilibrio importante que depende también de cada germen (por ejemplo, $S$. pneumoniae compite con $S$. viridans o $S$. aureus, pero tiene una relación positiva con N. meningitidis, de forma que el crecimiento de neumococos en la nasofaringe se incrementa en presencia de colonias de meningococo) $)^{2}$. Se ha demostrado también que muchas infecciones virales facilitan la adhesión de neumococos a la mucosa de la vía respiratoria ${ }^{18}$ y por ello se aíslan más neumococos en la nasofaringe de niños con procesos catarrales. Además de estas interacciones "ecológicas", existen factores del entorno determinantes de las modificaciones de la flora nasofaríngea. En conjunto, una serie de estos factores aumentan la posibilidad de portar neumococo en la infancia, y van desde el tamaño de la familia (sobre todo en relación al número de hermanos y al hacinamiento), a los ingresos familiares, el tabaquismo pasivo y activo, la asistencia o no a guarderías y centros escolares, y la infección viral concomitante ${ }^{2}$. Además, la colonización neumocócica, así como la ENI, es más prevalente en determinadas etnias, como afroamericanos, indios Apache y 
Navajo, población nativa de Alaska y población aborigen australiana ${ }^{2}$. Por último, es más frecuente el estado de portador en niños que han recibido un tratamiento antibiótico reciente, en cuyo caso es más prevalente la colonización por cepas resistentes a antibióticos ${ }^{19}$.

Los polisacáridos capsulares (que definen cada serotipo) son ampliamente heterogéneos, pero muy inmunógenos $y$, a la vez, son el principal factor que define la virulencia, pues protegen a la bacteria de la fagocitosis ${ }^{20}$. La antigenicidad de los polisacáridos capsulares es tipo-específica, aunque puede darse la posibilidad de reacción cruzada entre serotipos (dentro del mismo serogrupo), ya que comparten polisacáridos en su composición capsular.

Está comprobado que el lugar donde mayores resistencias a antimicrobianos adquieren los neumococos es la nasofaringe del niño sano, y por un doble mecanismo: de selección de cepas sometidas con frecuencia a presión antibiótica (los tratamientos antibióticos en la primera infancia son bastante más habituales que en el resto de la niñez y que en la edad adulta), y en segundo lugar por transmisión de material genético entre cepas diferentes que compiten por el mismo nicho ecológico. Esta es la razón por la que las cepas con menor capacidad invasiva (y que, por tanto, suelen permanecer bastante más tiempo colonizando la nasofaringe) coinciden con las que más resistencias a antibióticos desarrollan, y otros serotipos como el 1, el 5 o el 7F, difíciles de encontrar en la nasofaringe por su alta capacidad invasiva, no plantean problemas de resistencias a betalactámicos, macrólidos o quinolonas.

Independientemente de factores como la presión antibiótica o las vacunaciones, existe una variabilidad en el tiempo de la frecuencia de serotipos en la producción de ENI. Feikin ${ }^{21}$, en una amplia revisión en EE.UU. muestra cómo entre 1928 y 1998 la proporción de infecciones neumocócicas causadas por los siete serotipos vacunales (STV) aumentaron de un $15 \%$ a un $59 \%$ en adultos (13 estudios), y de un $53 \%$ a un $87 \%$ en niños (19 estudios). En los estudios nacionales de Fenoll22,23, con datos desde 1979 hasta 2008, se muestra una clara variabilidad en el tiempo en la incidencia de varios serotipos que han fluctuado antes ya de la utilización de la vacuna y en el global de la población (serotipos 1, 5, 7F, 23F) frente a otros con una incidencia más estable (serotipos 3, 4, 6A, 8). Esta variabilidad puede estar condicionada por los cambios en la utilización de antibióticos, las condiciones socioeconómicas de las poblaciones, el estado inmunológico y también la práctica más extendida con el 
tiempo de hemocultivos en la investigación de las infecciones.

La eficacia de la VNC-7 en la erradicación de la colonización nasofaríngea por cepas incluidas en esa vacuna parece estar en relación directa con la capacidad de producir anticuerpos de tipo IgA e IgG antipolisacáridos en la mucosa bucal, hecho que, según se ha demostrado, se da principalmente tras la dosis de refuerzo ${ }^{24}$.

Finalmente, hay que constatar que los cambios que han sucedido tras la introducción de la vacuna conjugada entre los neumococos ahora responsables de la ENI se correlacionan bien con los habidos en portadores sanos de las mismas poblaciones, con la única excepción de los serotipos mencionados antes como de mayor capacidad invasiva, que lógicamente eran infrecuentes colonizadores en la era prevacunal, y lo siguen siendo ahora ${ }^{11,25-28}$.

Según lo expuesto, parece importante concluir que es esencial mantener monitorizada la evolución de serotipos que colonizan la nasofaringe de los niños pequeños, ya que en esa distribución de serotipos encontraremos los que van a producir ENI, conoceremos cómo evoluciona la adquisición de resistencias antibióticas y, en función de ello, podremos elaborar estrategias vacunales que inclu- yan los serotipos emergentes. No obstante, hay que tener en cuenta que ciertos serotipos y genotipos muestran una mayor predisposición a la ENI en relación con su escasa presencia en la nasofaringe (serotipos 14, 1, 5, 7F, 8, 38, 33F, y clones del 18C), y van a estar porcentualmente en escasa cantidad respecto a otras cepas de menos invasividad. Por ello, aun a pesar de su escasa presencia en la nasofaringe, los serotipos 1, 5, y 7F han sido incluidos en las nuevas vacunas deca- $y$ tridecavalente.

\section{Los serotipos de neumococo \\ y su capacidad invasiva}

Determinados serotipos se hallan con más frecuencia entre portadores sanos ${ }^{2}$. Antes de la era vacunal, estos eran los incluidos en la vacuna VNC-7, a excepción del serotipo 4, así como los serotipos relacionados 6A, 19A, y el serotipo 3 (incluidos todos ellos en la VNC-13), y otros pertenecientes a lo serogrupos 10, 11, 15 y 33. Por el contrario, los serotipos 1 , $5,7 F, 8$ y 46 se encuentran muy ocasionalmente en portadores sanos, incluso en poblaciones entre las que producen importantes porcentajes de enfermedades invasivas.

Está comprobado, y se confirmó de nuevo en el metaanálisis de Brueggemann ${ }^{17}$, que serotipos y serogrupos de 
neumococo difieren en su capacidad invasiva. Este autor calcula, con los datos de los diferentes estudios incluidos (siete estudios, todos de la era prevacunal), la odds ratio (OR) entre neumococos de cada serogrupo encontrados en la orofaringe de población sana y los encontrados en la misma población en enfermedad invasiva, y concluye finalmente que los serogrupos más invasivos serían 1, 4, 5,7 y 14. Esto concuerda además con el hallazgo de que los serogrupos con mayor capacidad invasiva fueron los menos frecuentemente portados. Sandgren ${ }^{29}$ estudia en Suecia la capacidad invasiva de los diferentes serotipos relacionando las características de 273 aislamientos en ENI y 246 tomados de niños portadores en guarderías. Finalmente, los 34 serotipos aislados se pueden agrupar para el autor en dos clases: los que producen fundamentalmente ENI (1, 4, 7F y 9V) muy relacionados "clonalmente", y los que causan ENI pero también se hallan frecuentemente colonizando la nasofaringe (6A, 6B, 14 y 19F), que son genéticamente más variados. Aislamientos pertenecientes a un mismo clon se encontraron con diferentes cápsulas (serotipos) y se constató que tenían similar potencial de patogenicidad, por lo que las propiedades asociadas a un tipo clonal en particular se sumarían a las especí- ficas de la cápsula para determinar la invasividad. Además, algunas investigaciones $^{30}$ sugieren que existe heterogeneidad entre tipos capsulares y resultados de capacidad invasiva según las características del huésped humano: los serotipos más invasivos y portados brevemente en la nasofaringe suelen infectar a pacientes con poca o nula comorbilidad, causan enfermedad menos grave y se asocian con menor mortalidad. Por el contrario, los serotipos menos invasivos y portados durante mayores periodos en la nasofaringe suelen infectar a pacientes con mayor comorbilidad, causar enfermedad más grave y provocar mayor mortalidad.

Aunque el polisacárido capsular de cada serotipo de neumococo parece el factor más importante asociado a su virulencia, genes de otras proteínas de la bacteria también podrían contribuir a su potencial patogenicidad. De hecho, para otras bacterias encapsuladas como $\mathrm{N}$. meningitidis hay evidencia de que las variaciones clonales que determinan elementos no capsulares pueden ser mejores predictores de virulencia que la identidad capsular ${ }^{31}$.

Aunque todos los serotipos pueden causar cualquier tipo de ENI, es bien conocido que algunos de ellos manifiestan especial predisposición a producir una enfermedad invasiva concreta, como el 
caso del serotipo 1 y las neumonías complicadas con empiema en niños mayores de dos años, o los serogrupos 6, 10 y 23 y las meningitis ${ }^{22}$. Además, también hay diferencias en la incidencia de determinados serotipos según la edad del paciente. Así, en niños menores de cinco años son especialmente incidentes los serotipos $1,3,5,7 F$, y $19 \mathrm{~A}$ y mucho más a raíz de la introducción de la VNC-7, que no los incluía. La proporción de infecciones causadas por los siete serotipos "pediátricos" incluidos en la vacuna es más baja en adultos en todas las regiones geográficas ${ }^{32}$ y más todavía tras la introducción de la vacuna. Con todo, estos siete serotipos constituían la etiología del 59\% de todas las ENI en adultos en 1998 en EE.UU. ${ }^{21}$. En adultos más mayores se ha demostrado en casi todas las áreas geográficas una mayor incidencia de determinados serotipos (6B, 8, 14 y 23F).

\section{Los serotipos de neumococo}

\section{y sus resistencias a antibióticos}

La selección de cepas resistentes a antibióticos sucede fundamentalmente en la nasofaringe de los portadores. Por ello, hay una correlación bastante consistente entre los serotipos más frecuentemente aislados en la nasofaringe y aquellos con más resistencias a antimicrobianos ${ }^{33}$. Además, el conocimiento de diferentes clones comunes a varios serotipos (muy prevalente fue el "Spanish 23F clone") asociados con multirresistencia neumocócica a antibióticos ha permitido demostrar un importante papel de estas dotaciones genéticas en las resistencias de diferentes serotipos de neumococo, ya que se ha podido demostrar que unos pocos clones se encuentran detrás de más del $80 \%$ de las cepas (aun de diferentes serotipos) multirresistentes ${ }^{34}$. Por tanto, los periodos más prolongados en la nasofaringe permiten un mayor intercambio genético entre los diferentes serotipos y, en último término, mayor probabilidad de adquisición de resistencias a antimicrobianos.

Clásicamente, los serotipos más relacionados con resistencias a antimicrobianos han sido 6A, 6B, 9V, 14, 19A, 19F y $23 F^{31}$. Además de la selección natural ante la presión antibiótica y del intercambio de material genético, se ha descrito (y demostrado in vitro) un fenómeno implicado en la adquisición de resistencias, denominado de "transformación capsular" (capsular switching), de manera que algún serotipo vacunal concreto (se ha comprobado con clones del 23F Spanish/US), mediante transferencia de material genético que determina la cápsula polisacárida procedente de otros serotipos no vacunales, ha podido resultar fi- 
nalmente en variantes de los serotipos 3 y $9 \mathrm{~N}^{35}$, con similares resistencias a betalactámicos y macrólidos. En una publicación israelí sobre aislados de otitis media supurada, se sugiere que la similitud entre los clones (y en el patrón de resistencias) encontrados en los serotipos no vacunales 15B/C y 11 y el STV 19F podría deberse a este mecanismo de transformación capsular ${ }^{36}$. Obviamente, este fenómeno se produciría en particular en aquellos serotipos más prolongadamente portados en la nasofaringe.

Respecto a la evolución de la sensibilidad a antimicrobianos, una vez introducida ampliamente la vacunación VCN-7, parece que a medida que se publican nuevos estudios los serotipos emergentes que inicialmente presentaron menores resistencias ${ }^{37}$ van adquiriéndolas ${ }^{38-43}$. En España, con datos del Laboratorio de Referencia de Neumococos del Instituto de Salud Carlos III, sobre un total de 25166 aislamientos de ENI en toda las edades y en el periodo 1979-2008, el número de neumococos no sensibles a penicilina (suma de resistencia intermedia y total) aumentó desde un $6 \%$ en 1979, hasta un máximo del $44 \%-45 \%$ en los años 1995-97, cuando empieza a declinar gracias a una utilización más racional de la terapia antibiótica hasta un $33,9 \%$ en 1999 , descenso que se hizo mayor a partir de 2002 (introducción de la vacuna), hasta ser del $22,3 \%$ en 2008 $(p<0,001)^{44}$. En el mismo estudio, las resistencias a macrólidos descendieron desde un $42,9 \%$ de cepas resistentes en ENI en niños en 2003 a un $26,6 \%$ en 2008. Destaca en otro amplio estudio nacional del mismo Laboratorio ${ }^{9}$ el hecho de que, comparando los periodos 1997 2001 y 2007-2008, cuatro STV disminuyeron significativamente entre el porcentaje de cepas resistentes a penicilina $(6 \mathrm{~B}$, 9V, 19F y 23F) y uno permaneció estable (serotipo 14), mientras que el porcentaje de serotipos no vacunales entre los no sensibles a penicilina aumentó significativamente, destacando el incremento de dos serotipos (19A y 24F).

En series amplias, tras la introducción de la vacuna conjugada, la evolución de los serotipos emergentes es hacia la adquisición de resistencias, facilitadas por la transmisión genética de estas, como ha sido el caso del serotipo 19A. Esta tendencia se confirma más certeramente en estudios prospectivos como los de Ghafarr $^{45}$ y Park $^{46}$.

\section{Modificaciones en la distribución de serotipos tras la introducción de la VNC-7}

Los serotipos incluidos en VNC-7 lo fueron por ser los más prevalentes como 
productores de ENI en niños preescolares de Norteamérica (EE.UU. y Canadá). En países europeos ${ }^{5}$ variaba con un $64 \%$ de STV entre los que producían ENI en esa población en Alemania, o un $85 \%$ en Inglaterra y Francia, o una estimación del $74 \%$ en España. En Australia se cubría un $80 \%-90 \%$ de $\mathrm{ENI}$, pero en Latinoamérica descendía a un $65 \%$, y en Asia aproximadamente a un $50 \%{ }^{32}$.

A partir de esa realidad de cada país, parece claramente comprobado que la introducción de la vacuna heptavalente, sobre todo en los que han conseguido muy amplias coberturas vacunales, ha supuesto un gran descenso de la carga de la ENI global en niños menores de seis años, como se puede demostrar en los casos en que se dispone de estudios rigurosos antes y después ${ }^{7,38,47-50}$. De forma inversa, y en las mismas poblaciones, es significativo el incremento de ENI por serotipos no incluidos en la vacuna heptavalente en todos los grupos de edad ${ }^{51-54}$, aunque la carga de enfermedad que estos producen es sensiblemente inferior a la provocada previamente por los vacunales, salvo en poblaciones de mayor riesgo de ENI, como la nativa de Alaska ${ }^{25}$ (entre los periodos 1995-2000 y 2004-2006 la incidencia de ENI producidas por STV en menores de dos años pasó de 275,3 a
10,6 por 100000 , mientras que las producidas por no vacunales se incrementaron de 95,1 a 228,6 por 100000 en los mismos periodos de tiempo). Algunos de los serotipos emergentes han mostrado importante patogenicidad (1, 19A) e incluso multirresistencias a antimicrobianos $(19 A)^{9,25,55-57}$.

En EE.UU., en un estudio que compara la evolución de las meningitis neumocócicas antes y después de la vacuna heptavalente, la incidencia global, para todas las edades, descendió de 1,13 casos por 100000 habitantes entre 1989-1999 a 0,79 por 100000 en el periodo 20042005 (30,1\% de descenso; $p<0,001$ ), descenso que para la tasa en menores de dos años fue hasta de un $64,0 \%$ $(p<0,001)^{38}$. La caída fue del $92,8 \%$ $(p<0,001)$, y del 73,3\% $(p<0,001)$ en cuanto a las meningitis producidas por STV en menores de dos años y en todas las edades, respectivamente. Sin embargo, el aumento de las meningitis producidas por serotipos no vacunales (excluidos los "relacionados" e incluido ahora el $19 A)$ fue de un $275,3 \%(p=0,001)$ y un $60,5 \%(p<0,001)$ en cada grupo.

En España, también han variado la proporción y las cepas causantes de ENI en niños menores de seis años tras la introducción de la vacuna. Se han publicado en nuestro país datos contradictorios 
sobre la efectividad de la vacunación en la reducción de la EN1 ${ }^{11,58-70}$. Seguramente, la discusión sobre la eficacia de la vacunación en nuestro país, y las cifras reales de incidencia, tenga que ver con las menores tasas de cobertura vacunal que se han venido dando, al ser una vacuna no financiada (salvo en Madrid, donde lo es desde noviembre de 2006), y con un aumento en la realización de hemocultivos en las comunidades autónomas (CCAA) en las que se han establecido sistemas de vigilancia epidemiológica sobre la ENI. Las diferentes tasas de incidencia en estudios postvacunales en España pueden comprobarse en la tabla 2.

Tabla 2. Evolución de la tasas de incidencia (por 100000 habitantes) de enfermedad neumocócica invasiva en niños en diferentes estudios relativos a España tras la introducción de la vacuna conjugada heptavalente

\begin{tabular}{|c|c|c|c|c|}
\hline Población/periodos & $\begin{array}{c}\text { Cobertura } \\
\text { VNC-7 }\end{array}$ & $\begin{array}{l}\text { Incidencia } \\
\text { en }<2 \text { años }\end{array}$ & $\begin{array}{c}\text { ENI por serotipos } \\
\text { no vacunales }\end{array}$ & Meningitis \\
\hline Navarra $^{59}$ & & & $<2$ años & $<5$ años \\
\hline 2001 & - & $99 / 100000$ & $61 / 100000(55 \%)$ & $9 \%$ de ENI \\
\hline 2005 & $27 \%$ & $115 / 100000$ & $99 / 100000(68 \%)$ & $0 \%$ de ENI \\
\hline Euskadi/Navarra ${ }^{60}$ & & & $<2$ años & $<5$ años \\
\hline 2001 & - & $93,5 / 100000$ & $19,2 / 100000$ & $7,9 / 100000$ \\
\hline 2003 & $28 \%-45 \%$ & $56,3 / 100000$ & $18,7 / 100000$ & $1,8 / 100000$ \\
\hline Cataluña ${ }^{66}$ & & & $<2$ años & $<2$ años \\
\hline 1997-99 & - & $49,2 / 100000$ & $29,5 \%$ & $6,0 / 100000$ \\
\hline 2002-04 & $35 \%$ & $40,4 / 100000$ & - & $4,3 / 100000$ \\
\hline 2005-07 & $50 \%-60 \%$ & - & $68,4 \%$ & - \\
\hline Barcelona $^{62}$ & & & $<2$ años & $<2$ años \\
\hline $1997-2001$ & - & $32,4 / 100000$ & $5,6 / 100000(17 \%)$ & $11,2 / 100000$ \\
\hline $2002-2006$ & $45 \%-50 \%$ & $51,3 / 100000$ & $35,2 / 100000(72 \%)$ & $10,7 / 100000$ \\
\hline Barcelona $^{11}$ & & (<5 años) & $<5$ años & $<5$ años \\
\hline $1999-2001$ & - & $96,9 / 100000$ & $21 \%$ & $3,4 / 100000$ \\
\hline $2002-2004$ & $33 \%$ & $90,6 / 100000$ & $43,7 \%$ & $1,4 / 100000$ \\
\hline Canarias $^{63}$ & & & $<2$ años & $<2$ años \\
\hline 2000-01 & - & $53,8 / 100000$ & $43,3 \%$ & - \\
\hline 2004-06 & $48 \%$ & $57,8 / 100000$ & $74,5 \%$ (año 2006) & $5,3 / 100000$ \\
\hline Madrid $^{73}$ & & (<5 años) & $<5$ años & $<5$ años \\
\hline 2003 & - & $19,4 / 100000$ & $41 \%$ & $5,98 / 100000$ \\
\hline 2007 & $67,2 \%$ & $10,1 / 100000$ & $89 \%$ & $4,6 / 100000$ \\
\hline Galicia $^{68}$ & & & & $<5$ años \\
\hline $1998-2000$ & - & $27,3 / 100000$ & $20 \%$ & $6,8 / 100000$ \\
\hline 2004-2006 & $54 \%$ & $47,9 / 100000$ & $72 \%$ & $2,4 / 100000$ \\
\hline Valencia $^{69}$ & & (<5 años) & & $<5$ años \\
\hline 2008 & $60 \%$ & $32,8 / 100000$ & $85,7 \%$ & $5,3 / 100000$ \\
\hline
\end{tabular}

ENI: enfermedad neumocócica invasiva; VCN-7: vacuna conjugada heptavalente. 
En nuestro país, los serotipos que actualmente producen la mayoría de las ENI en niños son 19A, 1, 6A, 7F, 5, 3, 24F y serogrupo 15, y de los vacunales aún persiste con mantenida incidencia el $14^{11,22,59,62-65,70-73}$, mientras que los que previamente las producían, por orden de frecuencia y en menores de dos años según datos del Laboratorio Nacional de Referencia de Neumococos ${ }^{22}$, eran 14, 19F, 6B, 23F, 6A, 19A, 18C y 9V, y en niños de dos a cinco años eran 14, 18C, 1, 6B, 19F, 23F, 6A y 9V. Además, se mantienen algunas peculiaridades locales, como el caso de un brote de ENI por serotipo 5 en Madrd $^{70,73}$, que afectó sobre todo a niños de uno a cuatro años en forma de neumonía bacteriémica, y de bacteriemia.

Es preciso comentar uno de los hechos más destacados coincidentes o consecuentes a la introducción de la VCN-7, y que ha sido el importante aumento de los ingresos hospitalarios por neumonías con empiema en niños (por ejemplo, un número 13 veces superior de los ingresos por este motivo en los hospitales de SeviIla y Málaga entre 1998 y 2006, o un incremento de seis veces en los hospitales de Barcelona de 2004 a 2006) ${ }^{72}$. En el $48 \%$ de este grupo de niños con neumonía complicada se demostró (mediante proteína $C$ reactiva [PCR], pruebas gené- ticas y/o cultivo) el serotipo 1 como causante. Solamente un $11 \%$ fueron producidas por STV. Este aumento de empiemas coincidente con la introducción de la vacuna conjugada se ha constatado en muchos otros países ${ }^{74-86}$.

En cuanto a la efectividad de la vacuna conjugada en enfermedad no invasiva, dos revisiones sistemáticas de la colaboración Cochrane sirven para valorarla. La primera ${ }^{87}$ estudia la eficacia en la prevención de las neumonías demostradas mediante radiografía según criterios de la OMS en niños menores de cinco años de edad, y desvela una eficacia vacunal (vacunas de 7, 9 u 11 serotipos) del 27\% (intervalo de confianza del 95\% [IC 95\%]: $15 \%$ a $36 \%$ ), pero esta disminuye a un $6 \%$ (IC 95\%: $2 \%$ a $9 \%$ ) al referirse al global de neumonías de diagnóstico clínico. En la segunda ${ }^{88}$, se valora el efecto de vacunas conjugadas de 7,9 u 11 serotipos sobre la incidencia de otitis media aguda (OMA) en menores de 12 años de edad, comprobándose una reducción del riesgo de OMA del 6\% (IC 95\%: $-4 \%$ a $16 \%$ ) para la VNC-7, y una reducción del 34\% (IC 95\%: 21\% a $44 \%$ ) en el caso de la vacuna 11-valente que utiliza como carrier la proteína $D$ de H. influenzae.

A propósito del papel de la vacuna en la prevención de la OMA, un reciente es- 
tudio estadounidense (prospectivo, sobre 200 niños de 6 a 30 meses de edad), muestra que si bien inicialmente tras la introducción de la vacuna el porcentaje de OMA atribuible a neumococo disminuyó de forma que las más frecuentes pasaron a ser las OMA por Haemophilus infuenzae no tipable (2001 a 2003), finalmente con datos de niños seguidos de 2007 a 2009, se demuestra que descendió hasta casi desaparecer la OMA producida por serotipos incluidos en la vacuna heptavalente, pero en la actualidad la producida por serotipos no vacunales (principalmente serotipos 19A, 6A, 6C y 15 en este estudio) vuelve a colocar al neumococo como principal causa de OMA en niños menores de tres años (37\% de otitis frente a $30 \%$ por Moraxella y $24 \%$ por Haemophilus ${ }^{89}$.

Es importante también constatar el efecto de inmunidad de grupo. Finalmente, la principal repercusión que la introducción de la VNC-7 en niños pequeños ha tenido sobre la ENI en adultos y ancianos ha sido una disminución en general no significativa de la incidencia global a esas edades, pero con una clara sustitución de serotipos, disminuyendo los STV y emergiendo los no vacunales ${ }^{90}$, hecho que se comprueba también en estudios nacionales (en el área sur de Barcelona en adultos se demuestran incre- mentos significativos entre el periodo 1997-2001 y el 2005-2007 de ENI por serotipos 1, 5, 7F, 12F, 19A, 22F y 24$)^{91}$.

En cuanto al estado de portador, se esperaba que, tal como sucedió con $H$. influenzae, el número de portadores sanos con la introducción de la VNC-7 disminuyera de forma significativa. Sin embargo, el resultado ha sido claramente el del fenómeno "del reemplazo", de manera que la disminución radical de STV como colonizadores da lugar a la sustitución por otros no incluidos en la VNC-7, manteniendo los mismos porcentajes de portadores en similares poblaciones. Las expectativas de lo que se denominó reactividad cruzada, si bien han sido algo efectivas para la mayoría de serotipos, han fracasado con la emergencia del serotipo 19A, cepas 23 noF y, en menor medida, del 6A.

Establecida previamente la importancia de la colonización nasofaríngea en la infección neumocócica, la irrupción de la vacuna también ha supuesto una selección de nuevas cepas, tanto en los niños como en los contactos ${ }^{27,90,91 .}$.

En nuestro país, pocos estudios se han publicado en relación con la evolución de los serotipos en niños portadores de neumococo en la nasofaringe. Solo existe publicado un estudio previo a la vacunación en España sobre colonización de 
neumococo en la nasofaringe de niños sanos $^{92}$. Se estudiaban niños sanos de seis años, entre los que se encuentra una tasa de portadores del 36,1\%, y llama la atención la gran cantidad de aislados no tipables encontrados (44,5\%). Del total, solamente un $27,3 \%$ de cepas eran de las incluidas en la VCN-7.

Después de la introducción de la vacuna se han publicado datos sobre la evolución de cepas en la nasofaringe de niños sanos en dos estudios. El primero, realizado en la ciudad de Sevilla ${ }^{10}$ a partir de muestras tomadas en centros de Atención Primaria y en un Servicio de Urgencias Pediátricas entre los años 2005 y 2006 a niños de entre seis meses y seis años, y con una tasa de cobertura vacunal estimada del $36 \%$, encuentra un porcentaje de portadores del 31\% y los serotipos más frecuentemente aislados fueron $6 \mathrm{~A}, 14,19 \mathrm{~A}$, serogrupo 15, $11 \mathrm{y}$ $23 \mathrm{~A}$ (no tipables $6 \%$ ). En conjunto, $21 \%$ son STV, similar porcentaje sería cubierto por la vacuna decavalente y un $42 \%$ de cepas por la tridecavalente. El segundo estudio se hace con muestras tomadas a niños menores de cinco años de Barcelona ${ }^{11}$ entre 2001 y 2005, con una tasa de cobertura vacunal estimada del $33 \%$, y sobre un porcentaje de portadores del $50 \%$ (las muestras se toman en un Servicio de Urgencias) los serotipos más fre- cuentemente aislados son $6 \mathrm{~A}, 9 \mathrm{~V}, 14,19$ (serogrupo, no se distinguieron serotipos dentro del 19) y 11 . En conjunto, el $34 \%$ son serotipos incluidos en VNC-7.

Además, habría que añadir el resultado de la investigación llevada a cabo por nuestro grupo en la provincia de Zarago$\mathrm{za}^{12}$ (en prensa) realizada sobre 371 niños de dos meses a cinco años de edad que acudían a revisiones de niño sano en tres centros de salud urbanos y uno rural durante un año, de 2008 a 2009, que desvela un porcentaje de portadores del $31 \%$, y que con una cobertura vacunal del $66 \%$ solamente encuentra STV en el 8,7\% de los niños colonizados. Los que más frecuentemente colonizaban la nasofaringe fueron el serogrupo 15 (15B/15C), y los serotipos 19A, 6A, 11, 22F, 23A y 31 . Un $8 \%$ fueron cepas no tipables.

En el entorno europeo y de países desarrollados, los datos sobre estudios en portadores sanos, tras VCN-7 son similares a los nuestros. Varía el porcentaje de portadores fundamentalmente en función de que las muestras sean tomadas en niños que acuden a consulta por revisiones del niño sano (sobre el 30\% de portadores) o niños que acuden a guarderías y/o centros de Educación Infantil (40\%-60\% de portadores). Pueden verse resumidos en la tabla 3 y, en conjunto, se demuestra que con coberturas vacunales por encima 
Tabla 3. Evolución de serotipos en niños portadores sanos tras la introducción de la vacuna heptavalente en diferentes países

\begin{tabular}{|c|c|c|c|c|c|}
\hline País $s^{\text {referencia } / a n ̃ o / s ~}$ & $\operatorname{Edad}(n)$ & $\begin{array}{c}\% \\
\text { portadores }\end{array}$ & $\begin{array}{l}\text { Cobertura } \\
\text { VCN-7 }\end{array}$ & \% STV & $\begin{array}{c}\text { ST más } \\
\text { frecuentes }\end{array}$ \\
\hline $\begin{array}{l}\text { España }^{12} \\
2009\end{array}$ & $\begin{array}{c}2 \mathrm{~ms}-5 \mathrm{a} \\
(371)\end{array}$ & $31 \%$ & $66 \%$ & $8,7 \%$ & $\begin{array}{c}15 \mathrm{~B} / \mathrm{C}, 19 \mathrm{~A} \\
6 \mathrm{~A}, 11\end{array}$ \\
\hline $\begin{array}{l}\text { Portuga| }{ }^{93} \\
2007\end{array}$ & $\begin{array}{c}6 \mathrm{~ms}-6 \mathrm{a} \\
(561)\end{array}$ & $61,3 \%$ & $76,7 \%$ & $20,7 \%$ & $\begin{array}{c}23 \mathrm{~A} / \mathrm{B}, 19 \mathrm{~F} \\
16 \mathrm{~F}, 19 \mathrm{~A}\end{array}$ \\
\hline $\begin{array}{l}\text { Noruega }^{94} \\
2006- \\
2008\end{array}$ & $\begin{array}{l}\text { Preescolares } \\
(611) \\
(608)\end{array}$ & $\begin{array}{l}77,7 \%{ }^{*} \\
80,4 \%{ }^{*}\end{array}$ & $\begin{array}{r}3,4 \% \\
39,2 \%\end{array}$ & $\begin{array}{l}43,6 \% \\
20,6 \%\end{array}$ & \\
\hline $\begin{array}{l}\text { Francia }^{95} \\
1999 \\
2006\end{array}$ & $\begin{array}{c}3 \mathrm{~ms}-3 \mathrm{a} \\
(298) \\
(335)\end{array}$ & $\begin{array}{c}54 \% \\
50,1 \%\end{array}$ & $\begin{array}{c}- \\
68 \%\end{array}$ & $\begin{array}{c}76,5 \% \\
21 \%\end{array}$ & 23-NoF, 6A, 19A \\
\hline $\begin{array}{l}\text { Grecia }^{96} \\
2005 \\
2007\end{array}$ & $\begin{array}{c}13-76 \mathrm{~ms} \\
(759) \\
(566)\end{array}$ & $\begin{array}{l}48 \% \\
51 \%\end{array}$ & $\begin{array}{l}13 \% \\
70 \%\end{array}$ & $\begin{array}{l}35,7 \% \\
11,7 \%\end{array}$ & $6 \mathrm{~A}, 23 \mathrm{~A}, 22 \mathrm{~F}, 38$ \\
\hline $\begin{array}{l}\text { USA-Massachussets }^{26} \\
2001 \\
2004\end{array}$ & $\begin{array}{l}<7 a \\
(742) \\
(994)\end{array}$ & $\begin{array}{l}26 \% \\
23 \%\end{array}$ & $\begin{array}{l}60 \% \\
96 \%\end{array}$ & $\begin{array}{l}36 \% \\
14 \%\end{array}$ & $15,19 A, 6 A, 29$ \\
\hline $\begin{array}{l}\text { USA-Alaska }{ }^{46} \\
2000 \\
2004\end{array}$ & $\begin{array}{c}3 \mathrm{~ms}-5 \mathrm{a} \\
(550) \\
(550)\end{array}$ & $\begin{array}{l}38 \% \\
41 \%\end{array}$ & $\begin{array}{c}- \\
89 \%\end{array}$ & $\begin{array}{l}54 \% \\
9,5 \%\end{array}$ & $11 \mathrm{~A}, 15,19 \mathrm{~A}, 35 \mathrm{~B}$ \\
\hline $\begin{array}{l}\text { USA-Indios Apache y Navajo97 } \\
\text { VNC-7 vacuna } \\
\text { MenigoC vacuna }\end{array}$ & $\begin{array}{l}1-18 \mathrm{~ms} \\
(227) \\
(226)\end{array}$ & $\begin{array}{l}72 \% \\
62 \%\end{array}$ & $\begin{array}{c}100 \% \\
0 \%\end{array}$ & $\begin{array}{l}21,6 \% \\
40,0 \%\end{array}$ & $6 \mathrm{~A}, 19 \mathrm{~F}, 19 \mathrm{~A}, 14$ \\
\hline $\begin{array}{l}\text { Canadá27 } \\
2003 \\
2005\end{array}$ & $\begin{array}{l}<6 a \\
(485) \\
(591)\end{array}$ & $20 \%$ & $\begin{array}{c}- \\
98 \%\end{array}$ & $\begin{array}{c}68 \% \\
22,3 \%\end{array}$ & $6 \mathrm{~A}, 15 \mathrm{C} / \mathrm{B}, 19 \mathrm{~F}, 6 \mathrm{~B}$ \\
\hline
\end{tabular}

* Se aplicaron otras técnicas de detección además del cultivo tradicional.

a: años; ms: meses; ST: serotipo; STV: serotipos incluidos en la vacuna heptavalente; USA: Estados Unidos;

VCN-7: vacuna conjugada heptavalente.

del $75 \%$ el porcentaje de STV que colonizan la nasofaringe no llega prácticamente al $20 \%$ 12,26,27,46,93-97. Los serotipos que en la era posvacunal se encuentran en la nasofaringe son también los que emergen como productores de ENI (19A, 6A, serogrupo 15, 23 noF, serogrupo 11), a excepción de los considerados más invasi- vos $(1,5,7 F)$ que, como cabía esperar, son difíciles de encontrar colonizando la nasofaringe de niños sanos.

\section{Perspectivas de futuro}

Ha quedado suficientemente demostrado que la vacuna PCV-7 ha evitado gran cantidad de ENI por STV, pero si 
hemos de sustituirla ahora por una de mayor número de serotipos es indudable que ha sido por la pujanza de nuevos serotipos por el llamado fenómeno "de reemplazo". En el haber de la heptavalente están no solo todas las ENI por STV evitadas desde la introducción de la vacuna, sino también las no invasivas evitadas, que lo han sido en menor porcentaje, pero que al ser mucho más frecuentes que las invasivas suponen una carga de enfermedad evitada muy considerable. Pero, al disminuir las probabilidades de ENI de los que la vacuna protege, la heptavalente pierde efectividad y deja de ser coste-efectiva ${ }^{98,99}$.

Además, con las nuevas formulaciones de vacunas conjugadas se plantean nuevos interrogantes: por ejemplo, la inclusión en la vacuna de serotipos muy frecuentes en la nasofaringe ha permitido casi su erradicación, pero la presencia ahora en las nuevas vacunas conjugadas de otros serotipos que apenas se encuentran colonizando la nasofaringe ( 1 , $5,7 F)$ crea dudas sobre la evolución de las ENI por estos serotipos, ya que no se produce tanta inmunidad de grupo al no sumarse el fenómeno de eliminación en portadores. También es importante conocer que en algunas poblaciones, en el momento de la introducción de la VCN13 partimos ya de una situación en la que los serotipos no incluidos en la 13valente suponen un número importante de causas de ENI: en EE.UU. ya 1/3 de ellas en $<5$ años, con muestras recogidas en 2007-2008, eran producidas por cepas no incluidas en la 13-valente ${ }^{7}$.

El fenómeno de inmunidad de grupo ha sido importante no en cuanto a la reducción de la carga global de la enfermedad neumocócica en adultos y ancianos (tema debatido, pero que en la mayoría de poblaciones ha permanecido con una incidencia más o menos estable), sino con respecto a la modificación en la distribución de serotipos causantes de ENI, constatándose también el fenómeno de reemplazo de STV por no vacunales. Con datos del Laboratorio Nacional de Referencia ${ }^{22}$, en adultos en la era prevacunal los STV producían el $41 \%$ de las ENI, y en el año 2008 solamente el $19 \%$.

Actualmente ya está comercializada en España (desde junio de 2010, Prevenar13 ${ }^{\oplus}$ ) la nueva vacuna 13 -valente, que cubre un espectro de serotipos más amplio y, a diferencia de la 10-valente (comercializada en agosto de 2009, Synflo$\mathrm{rix}^{\circledR}$ ), incluye el serotipo más frecuente en colonización y entre los productores de ENI actualmente en menores de dos años: el serotipo $19 A^{10-12,23,70}$. Sin entrar a valorar sus efectos tangenciales sobre la OMA, ya que la vacuna se ha diseñado 
para la prevención de las ENI en niños pequeños, cubriremos mejor el espectro actual de la ENI con la tridecavalente. $Y$ no solo porque en los estudios de portadores abarcamos el doble de serotipos hallados en la nasofaringe $\mathrm{e}^{10,12}$ con la tridecavalente respecto a la decavalente, sino por los datos actualizados en 2008 de los serotipos productores de ENI en niños españoles que facilita el Laboratorio de Referencia de Neumococos ${ }^{22}$ y en el que comprobamos que VNC-7 solamente cubriría ya el $13 \%$ de ENI en niños menores de dos años y el $16 \%$ en niños de entre dos y cinco años, mientras que VNC-10 cubriría el $39 \%$ y el $71 \%$ de ENI en ambos grupos de edad, y VNC13 protegería del $77 \%$ y el $88 \%$ de ENI en los dos grupos de edad. En nuestro entorno, en Francia se ha estimado que en niños menores de dos años VNC-10 protegería del $51 \%$ de ENI y VNC-13 del $76 \%$, y en Alemania del $57 \%$ y el $80 \%$ respectivamente ${ }^{39}$.

El logro principal (disminuir las tasas de ENI en niños menores de cinco años) de la vacuna conjugada parece estable en el tiempo, con coberturas vacunales altas, a excepción de lo que puede suceder en poblaciones particularmente susceptibles a las ENI, en las que la carga de la enfermedad por serotipos no incluidos en la vacuna termina siendo también eleva- $\mathrm{da}^{25}$. En un escenario de aplicación generalizada de vacuna tridecavalente, y si el comportamiento es similar a lo sucedido tras la introducción de la VCN-7, cabe esperar que se reduzca todavía más la incidencia de ENI y que, aunque nuevos serotipos reemplacen a los anteriores, la carga global de la enfermedad siga disminuyendo.

Con seguridad, nuevos serotipos tomarán protagonismo tras la generalización de la vacuna tridecavalente. Ya es una realidad que ciertos serotipos no incluidos en dicha vacuna se detectan de forma progresivamente más incidente tanto como productores de ENI como en portadores sanos ${ }^{100}$ (En EE.UU. y en Europa los serotipos 15A, 15B, 22F, 23A, $24 \mathrm{~F}, 33 \mathrm{~F}$ y 35B). La preocupación se concentra todavía más en serotipos que ya presentan clones ampliamente diseminados con importantes tasas de no sensibilidad a penicilina, como son 15A, $23 \mathrm{~A}$ y $35 \mathrm{~B}$, y que podrían resultar finalmente en un comportamiento similar al mostrado por el $19 \mathrm{~A}^{101}$.

Publicaciones recientes ${ }^{102}$ muestran que en portadores una vacuna 11-valente provoca similar efecto que la hepavalente: tras la dosis booster el porcentaje de portadores de neumococo es similar al del grupo control (sobre el $23 \%$ ), no se reduce; además, hay una caída del 
$48 \%$ en el total de serotipos incluidos en la 11-valente que colonizan la nasofaringe en el grupo vacunado con respecto al control, y ya se detecta un aumento de cepas no vacunales en aquel grupo (15,3\% de incremento).

Ante este escenario de incertidumbre, y dado que la técnica de conjugación parece no soportar muchos más serotipos en una misma vacuna que los que incluye la tridecavalente, se hace necesario el desarrollo de nuevas vacunas con dianas diferentes a los polisacáridos capsulares. La mejor estrategia parece que sería desarrollar una vacuna a partir de alguna proteína común a todos los neumococos, o una combinación de proteínas que cubriese eficientemente todas las cepas ${ }^{2,100}$. Se experimenta con varias candidatas (proteína A de la superficie, proteína A ligadora de colina, neumolisina) y la vacuna ideal probablemente sería la que consiguiese evitar tanto la colonización nasofaríngea como la extensión de las bacterias en forma de $\mathrm{ENI}^{103}$.
Finalmente, y aunque el autor de este artículo piensa que es una decisión que escapa al ámbito de los pediatras clínicos y que deberían tomarla expertos en salud pública y economía de la salud, por los datos y la experiencia obtenida con la VCN-7 parece necesario que se replantee la idoneidad de incluir la nueva vacuna tridecavalente en los calendarios vacunales de todo el país. Las desigualdades sociales que se crean ante una vacuna de elevado coste en farmacias y que compran aproximadamente un $75 \%$ de padres en las comunidades en que no está financiada, el hecho constatado de que a mayores coberturas mayor reducción de la carga global de la ENI en menores de cinco años, la seguridad de poder utilizar una pauta $2+1$ en lugar de 3 +1 cuando las coberturas son muy amplias, y la protección actual que ofrece la vacuna tridecavalente $(80 \%$ de serotipos productores de ENI en menores de cinco años) son factores que deberían tenerse en cuenta.

\section{Bibliografía}

1. Musher DM. Streptococcus pneumoniae. En: Mandell GL, Bennett JE, Dolin R (eds.). Enfermedades Infecciosas. Principios y práctica. Buenos Aires: Editorial Médica Panamericana; 2002. p. 2582-604.
2. Bogaert $D$, De Groot $R$, Hermans PW. Streptococcus pneumoniae colonisation: the key to pneumococcal disease. Lancet Infect Dis. 2004; 4:144-54.

3. World Health Organization. Pneumococcal conjugate vaccine for childhood immunization: 
WHO position paper. Wkly Epidemiol Rec. 2007; 82:93-104.

4. Hausdorff WP, Siber G, Paradiso PR. Geographical differences in invasive pneumococcal disease rates and serotype frequency in young children. Lancet. 2001;357:950-2.

5. Jefferson T, Ferroni E, Curtale F, Rossi PG, Borgia P. Streptococcus pneumoniae in western Europe: serotype distribution and incidence in children less than 2 years old. Lancet Infect Dis. 2006; 6:405-10.

6. Fedson DS, Scott JAG. The burden of pneumococcal disease among adults in developed and developing countries: what is and is not known. Vaccine. 1999;17(suppl. 1):S11-8.

7. Centers for Disease Control and Prevention. Invasive Pneumococcal Disease in Young Children Before Licensure of 13-Valent Pneumococcal Conjugate Vaccine-United States, 2007. MMWR. 2010;59:253-7.

8. De Carvalho Gomes $\mathrm{H}$, Muscat $\mathrm{M}$, Monnet DL, Giesecke J, Lopalco PL. Use of seven-valent pneumococcal conjugate vaccine (PCV7) in Europe, 2001-2007. Euro Surveill. 2009;14(12). pii: 19159.

9. Fenoll A, Granizo JJ, Aguilar L, Giménez MJ, Aragoneses-Fenoll $L$, Hanquet $G$ et al. Temporal trends of invasive Streptococcus pneumoniae serotypes and antimicrobial resistance patterns in Spain from 1979 to 2007. J Clin Microbiol. 2009; 47:1012-20.

10. Sánchez-Tatay D, Arroyo LA, Tarragó D, Lirola MJ, Porras A, Fenoll A et al. Antibiotic susceptibility and molecular epidemiology of nasopharyngeal pneumococci from Spanish children. Clin Microbiol Infect. 2008;14:797-801.

11. Calbo $E$, Díaz A, Cañadell E, Fábrega J, Uriz $S$, Xercavins $M$ et al. Invasive pneumococcal disease among children in a health district of Barcelona: early impact of pneumococcal conjugate vaccine. Clin Microbiol Infect. 2006;12:867-72.
12. García-Vera C, Ruiz Andrés MA, Arana Navarro T, Moneo Hernández I, Castillo Laita JA, Macipe Costa $R$, y cols. Serotipos de neumococo en la nasofaringe de niños preescolares sanos tras la vacunación antineumocócica conjugada heptavalente. Med Clin (Barc). 2010 (en prensa).

13. O'Brien KL, Nohynek H; World Health Organization Pneumococcal Vaccine Trials Carriage Working Group. Report from a WHO Working Group: standard method for detecting upper respiratory carriage of Streptococcus pneumoniae. Pediatr Infect Dis J. 2003;22:e1-11.

14. San José González MA, Méndez Fernández P. Vacuna conjugada neumocócica heptavalente: ¿luces y sombras? Rev Pediatr Aten Primaria. 2008; 10:467-88.

15. Dagan R, Givon-Lavi N, Zamir O, SikulerCohen M, Guy L, Janco J et al. Reduction of nasopharyngeal carriage of Streptococcus pneumoniae after administration of a 9-valent pneumococcal conjugate vaccine to toddlers attending day care centers. J Infect Dis. 2002;185:927-36.

16. Shouval DS, Greenberg D, Givon-Lavi N, Porat N, Dagan R. Site-specific disease potential of individual Streptococcus pneumoniae serotypes in pediatric invasive disease, acute otitis media and acute conjunctivitis. Pediatr Infect Dis J. 2006;25: 602-7.

17. Brueggemann $A B$, Peto $T E$, Crook DW, Butler JC, Kristinsson KG, Spratt BG. Temporal and geographic stability of the serogroup-specific invasive disease potential of Streptococcus pneumoniae in children. J Infect Dis. 2004;190:1203-11.

18. Tuomanen El. The biology of pneumococcal infection. Pediatr Res. 1997;42:253-8.

19. Ghaffar F, Muniz LS, Katz K, et al. Effects of large dosages of amoxicillin/clavulanate or azithromycin on nasopharyngeal carriage of Streptococcus pneumoniae, Haemophilus influenzae, nonpneumococcal alphahemolytic streptococci, and 
Staphylococcus aureus in children with acute otitis media. Clin Infect Dis. 2002;34:1301-9.

20. Watson DA, Musher DM. A brief history of the pneumococcus in biomedical research. Semin Respir Infect. 1999;14:198-208.

21. Feikin DR, Klugman KP. Historical changes in pneumococcal serogroup distribution: implications for the era of pneumococcal conjugate vaccines. Clin Infect Dis. 2002;35:547-55.

22. Fenoll A. Tendencias temporales de los serotipos neumocócicos en España: 1979-2008. En: Nuevos Restos y Lecciones Aprendidas. II Reunión de Expertos en Vacunación Antineumocócica Conjugada. Abril 2009. Madrid: Wyeth Vaccines; 2009. p. 3.

23. Fenoll A, Jiménez MJ, Vicioso MD. Trends of the ten most prevalent pneumococal serotype among invasive isolates from children in the last 12 years in Spain. Presented at: 6th Annual Meeting of the World Society for Pediatric Infectious DiseasesWSPID. Buenos Aires, Argentina, 18-22 November 2009 (Abstract 262).

24. Nurkka $A$, Ahman $H$, Korkeila $M$, Jantti $V$, Kayhty $\mathrm{H}$, Eskola J. Serum and salivary anti-capsular antibodies in infants and children immunized with the heptavalent pneumococcal conjugate vaccine. Pediatr Infect Dis J. 2001;20:25-33.

25. Singleton RJ, Hennessy TW, Bulkow LR, Hammitt LL, Zulz T, Hurlburt DA et al. Invasive pneumococcal disease caused by nonvaccine serotypes among alaska native children with high levels of 7-valent pneumococcal conjugate vaccine coverage. JAMA. 2007;297:1784-92.

26. Huang SS, Platt R, Rifas-Shiman SL, Pelton SI, Goldmann D, Finkelstein JA. Post-PCV7 changes in colonizing pneumococcal serotypes in 16 Massachusetts communities, 2001 and 2004. Pediatrics. 2005;116:e408-13.

27. Kellner JD, Scheifele D, Vanderkooi OG, Macdonald J, Church DL, Tyrrell GJ. Effects of routine infant vaccination with the 7-valent pneumo- coccal conjugate vaccine on nasopharyngeal colonization with streptococcus pneumoniae in children in Calgary, Canada. Pediatr Infect Dis J. 2008;27:526-32.

28. Laval $C B$, de Andrade AL, Pimenta FC, de Andrade JG, de Oliveira RM, Silva SA et al. Serotypes of carriage and invasive isolates of Streptococcus pneumoniae in Brazilian children in the era of pneumococcal vaccines. Clin Microbiol Infect. 2006;12:50-5.

29. Sandgren A, Sjostrom $K$, Olsson-Liljequist $B$, Christensson B, Samuelsson A, Kronvall G et al. Effect of clonal and serotype-specific properties on the invasive capacity of Streptococcus pneumoniae. J Infect Dis. 2004;189:785-96.

30. Sjöström K, Spindler C, Ortqvist A, Kalin M, Sandgren A, Kuhlmann-Berezon $S$ et al. Clonal and capsular type decides whether pneumococci will act as a primary or opportunistic pathogen. Clin Infect Dis. 2005;42:451-9.

31. Hausdorff WP, Feikin DR, Klugman KP. Epidemiological differences among pneumococcal serotypes. Lancet Infect Dis. 2005;5:83-93.

32. Hausdorff WP, Bryant J, Paradiso PR, Siber GR. Which pneumococcal serogroups cause the most invasive disease: implications for conjugate vaccine formulation and use, part I. Clin Infect Dis. 2000;30:100-21.

33. Whitney CG, Farley MM, Hadler J, Harrison $\mathrm{LH}$, Lexau C, Reingold A et al. Increasing prevalence of multidrug-resistant Streptococcus pneumoniae in the United States. N Eng J Med. 2000;343: 1917-24.

34. Richter SS, Heilmann KP, Coffman SL, Huynh HK, Brueggemann AB, Pfaller MA et al. The molecular epidemiology of penicillin-resistant Streptococcus pneumoniae in the United States, 1994-2000. Clin Infect Dis. 2002;34:330-9.

35. Barnes DM, Whittier $S$, Gilligan $P H$, Soares $S$, Tomasz A, Henderson FW. Transmission of multidrug-resistant serotype 23F Streptococcus pneu- 
moniae in group day care: evidence suggesting capsular transformation of the resistant strain in vivo. J Infect Dis. 1995;171:890-6.

36. Porat N, Arguedas A, Spratt BG, Trefler R, Brilla $E$, Loaiza C, Godoy D et al. Emergence of penicillin-nonsusceptible Streptococcus pneumoniae clones expressing serotypes not present in the antipneumococcal conjugate vaccine. J Infect Dis. 2004;190:2154-61.

37. Dagan R, Klugman KP. Impact of conjugate pneumococcal vaccines on antibiotic resistance. Lancet Infect Dis. 2008;8:785-95.

38. Hsu HE, Shutt KA, Moore MR, Beall BW, Bennett NM, Craig AS, et al. Effect of pneumococcal conjugate vaccine on pneumococcal meningitis. N Engl J Med. 2009;360:244-56.

39. Isaacman DJ, McIntosh D, Reinert RR. Burden of invasive pneumococcal disease and serotype distribution hmong Streptococcus pneumoniae isolates in young children in Europe: impact of the 7-valent pneumococcal conjugate vaccine and considerations for future conjugate vaccines. Int J Infect Dis. 2010;14:e197-209.

40. Mera R, Miller LA, Fritsche TR, Jones RN. Serotype replacement and multiple resistance in Streptococcus pneumoniae after the introduction of the conjugate pneumococcal vaccine. Microb Drug Resist. 2008;14:101-7.

41. Farrell DJ, Klugman KP, Pichichero M. Increased antimicrobial resistance among nonvaccine serotypes of Streptococcus pneumoniae in the pediatric population after the introduction of 7-valent pneumococcal vaccine in the United States. Pediatr Infect Dis J. 2007;26:123-8.

42. Finkelstein JA, Huang SS, Daniel J, Rifas-Shiman SL, Kleinman K, Goldmann D et al. Antibioticresistant Streptococcus pneumoniae in the heptavalent pneumococcal conjugate vaccine era: predictors of carriage in a multicommunity sample. Pediatrics. 2003;112:862-9.
43. Frazão N, Brito-Avô A, Simas C, Saldanha J, Mato R, Nunes $S$ et al. Effect of the seven-valent conjugate pneumococcal vaccine on carriage and drug resistance of Streptococcus pneumoniae in healthy children attending day-care centers in Lisbon. Pediatr Infect Dis J. 2005;24: 243-52.

44. Liñares J, Ardanuy $C$, Pallares R, Fenoll A. Changes in antimicrobial resistance, serotypes and genotypes in Streptococcus pneumoniae over a 30-year period. Clin Microbiol Infect. 2010;16: 402-10.

45. Ghaffar F, Barton T, Lozano J, Muniz LS, Hicks P, Gan V et al. Effect of the 7-valent pneumococcal conjugate vaccine on nasopharyngeal colonization by Streptococcus pneumoniae in the first 2 years of life. Clin Infect Dis. 2004;39: 930-8.

46. Park SY, Moore MR, Bruden DL, Hyde TB, Reasonover AL, Harker-Jones $M$ et al. Impact of conjugate vaccine on transmission of antimicrobial-resistant Streptococcus pneumoniae among Alaskan children. Pediatr Infect Dis J. 2008;27: 335-40.

47. Centers for Disease Control and Prevention (CDC). Pneumonia hospitalizations among young children before and after introduction of pneumococcal conjugate vaccine, United States, 19972006. MMWR Morb Mortal Wkly Rep. 2009;58: $1-4$.

48. Grijalva CG, Nuorti JP, Arbogast PG, Martin SW, Edwards KM, Griffin MR. Decline in pneumonia admissions after routine childhood immunisation with pneumococcal conjugate vaccine in the USA: a time-series analysis. Lancet. 2007;369: 1179-86.

49. Reingold A, Hadler J, Farley MM, Harrison L, Lynfield R, Lexau C et al. Invasive Pneumococcal Disease in Children 5 Years After Conjugate Vaccine Intrduction. Eigth States 1998-2005. MMWR. 
Morbidity and Mortality Weekly Report. 2008;57: 144-7.

50. Pavia $M$, Bianco A, Nobile CG, Marinelli $P$, Angelillo IF. Efficacy of pneumococcal vaccination in children younger than 24 months: a meta-analysis. Pediatrics. 2009;123:e1103-10.

51. The UK Health Protection Agency. Current Epidemiology of Invasive Pneumococcal Disease (IPD) [Consultado el 31 de Julio de 2010]. Disponible en www.hpa.org.uk/HPA/Topics/Infectious Diseases/InfectionsAZ/1220341771909/.

52. Lepoutre A, Varon E, Georges S, Gutmann L, Lévy-Bruhl D. Impact of infant pneumococcal vaccination on invasive pneumococcal diseases in France, 2001-2006. Euro Surveill. 2008;13 (35). pii: 18962.

53. Rückinger $S$, Van der Linden $M$, Reinert $R R$, Von Kries R, Burckhardt F, Siedler A. Reduction in the incidence of invasive pneumococcal disease after general vaccination with 7-valent pneumococcal conjugate vaccine in Germany. Vaccine. 2009; 27:4136-41.

54. Durando $P$, Crovari $P$, Ansaldi $F$, Sticchi L, Sticchi C, Turello $V$ et al; Collaborative Group for Pneumococcal Vaccination in Liguria. Universal childhood immunisation against Streptococcus pneumoniae: the five-year experience of Liguria Region, Italy. Vaccine. 2009;27:3459-62.

55. Kyaw MH, Lynfield R, Schaffner W, Craig AS, Hadler J, Reingold A et al; Active Bacterial Core Surveillance of the Emerging Infections Program Network. Effect of introduction of the pneumococcal conjugate vaccine on drug-resistant Streptococcus pneumoniae. N Engl J Med. 2006;354:145563.

56. Picazo JJ. Management of antibiotic-resistant Streptococcus pneumoniae infections and the use of pneumococcal conjugate vaccines. Clin Microbiol Infect. 2009;15(Suppl. 3):4-6.
57. Mera R, Miller LA, Fritsche TR, Jones RN. Serotype replacement and multiple resistance in Streptococcus pneumoniae after the introduction of the conjugate pneumococcal vaccine. Microb Drug Resist. 2008;14:101-7.

58. Moore MR, Whitney CG. Emergence of nonvaccine serotypes following introduction of pneumococcal conjugate vaccine: cause and effect? Clin Infect Dis. 2008;46:183-5.

59. Barricarte A, Gil-Setas A, Torroba L, Castilla J, Petit A, Polo I et al. Invasive pneumococcal disease in children younger than 5 years in Navarra, Spain (2000-2005). Impact of the conjugate vaccine. Med Clin (Barc). 2007;129:41-5.

60. Aristegui J, Bernaola E, Pocheville I, García C, Arranz L, Durán G et al. Reduction in pediatric invasive pneumococcal disease in the Basque Country and Navarre, Spain, after introduction of the heptavalent pneumococcal conjugate vaccine. Eur J Clin Microbiol Infect Dis. 2007;26 303-10.

61. Guevara M, Barricarte A, Pérez B, Arriazu $M$, García Cenoz M, Castilla J. La vacuna neumocócica conjugada heptavalente (Prevenar $\left.{ }^{\circledR}\right)$. Diferencias en su efectividad en distintas poblaciones. An Sist Sanit Navar. 2008;31:171-92.

62. Muñoz-Almagro C, Jordan I, Gene A, Latorre C, Garcia-Garcia JJ, Pallares R. Emergence of invasive pneumococcal disease caused by nonvaccine serotypes in the era of 7-valent conjugate vaccine. Clin Infect Dis. 2008;46:174-82.

63. Artiles F, Horcajada I, Cañas AM, Alamo I, Bordes A, González A y cols. Aspectos epidemiológicos de la enfermedad neumocócica invasiva antes y después del uso de la vacuna neumocócica conjugada en Gran Canaria. Enferm Infecc Microbiol Clin. 2009;27:14-21.

64. Casado-Flores J, Rodrigo C, Arístegui J, Martínón JM, Fenoll A, Mendez C. Decline in pneumococcal meningitis in Spain after introduction of the 
heptavalent pneumococcal conjugate vaccine. Pediatr Infect Dis J. 2008;27:1020-2.

65. Benito-Fernández J, Raso SM, PochevilleGurutzeta I, Sánchez-Etxaniz J, Azcunaga-Santibañez B, Capapé-Zache S. Pneumococcal bacteremia among infants with fever without known source before and after introduction of pneumococcal conjugate vaccine in the Basque Country of Spain. Pediatr Infect Dis J. 2007;26:667-71.

66. Salleras L, Domínguez A, Ciruela P, Izquierdo C, Borràs E; Grupo de Trabajo del Sistema de Notificación Microbiológica de Cataluña. Impacto de la vacuna neumocócica conjugada heptavalente en una población con valores bajos-intermedios de vacunación. Enferm Infecc Microbiol Clin. 2009; 27:275-7.

67. Informe de la enfermedad neumocócica invasiva en la Comunidad de Madrid, año 2007. Boletín Epidemiológico de la Comunidad de Madrid. 2008;14:3-33.

68. Boletín Epidemiolóxico de Galicia. A enfermidade pneumocócica invasiva en Galicia: 20042006. 2007;20:4.

69. Direcció General de Salut Pública. Enfermedad neumocócica invasiva. Informe 2008 [Consultado el 31/07/2010]. Disponible en: www.sp.san. gva.es/DgspPortal/docs/Inf_Enf_Neumo_Inv_ 2008.pdf.

70. Picazo J, Ruiz-Contreras J, Casado-Flores J, Giangaspro E, Del Castillo F, Hernandez-Sampelayo $E$ et al. Serotype distribution of invasive streptococcus pneumoniae among hospitalized pediatric patients in Madrid (may 2007-april 2008) 27th Annual Meeting of the European Society for Paediatric Infectious Disease. Brussels, Belgium, June 2009. [P-204].

71. Salleras L, Domínguez A, Ciruela P, Izquierdo $\mathrm{C}$, Navas $\mathrm{E}$, Torner $\mathrm{N}$ et al. Changes in serotypes causing invasive pneumococcal disease (20052007 vs. 1997-1999) in children under 2 years of age in a population with intermediate coverage of the 7-valent pneumococcal conjugated vaccine. Clin Microbiol Infect. 2009;15:997-1001.

72. Obando I, Muñoz-Almagro C, Arroyo LA, Tarrago D, Sanchez-Tatay D, Moreno-Perez D et al. Pediatric parapneumonic empyema, Spain. Emerg Infect Dis. 2008; 14:1390-7.

73. Valera González A. Informe: enfermedad neumocócica invasiva en la Comunidad de Madrid. Descripción de serotipos. Boletín Epidemiológico de la Comunidad de Madrid. 2010;16:43-92.

74. Pilishvili T, Lexau C, Farley MM, Hadler J, Harrison LH, Bennett NM et al. Active Bacterial Core Surveillance/Emerging Infections Program Network. Sustained reductions in invasive pneumococcal disease in the era of conjugate vaccine. J Infect Dis. 2010;201:32-41.

75. Li ST, Tancredi DJ. Empyema hospitalizations increased in US children despite pneumococcal conjugate vaccine. Pediatrics. 2010;125:26-33.

76. Byington $\mathrm{CL}$, Korgenski K, Daly J, Ampofo K, Pavia A, Mason EO. Impact of the pneumococcal conjugate vaccine on pneumococcal parapneumonic empyema. Pediatr Infect Dis J. 2006; 25:250-4.

77. Weil-Olivier C, Levy C, Marguet C, Sardet A, de La Rocque $F$, Lecuyer $A$ et al. Enquête rétrospective multicentrique sur les pleuropneumopathies infectieuses de l'enfant en France. Arch Pediatr. 2005;12:823-6.

78. Hsieh YC, Hsueh PR, Lu CY, Lee PI, Lee CY, Huang LM. Clinical manifestations and molecular epidemiology of necrotizing pneumonia and empyema caused by Streptococcus pneumoniae in children in Taiwan. Clin Infect Dis. 2004;38:830-5.

79. Eastham KM, Freeman R, Kearns AM, Eltringham G, Clark J, Leeming J et al. Clinical features, aetiology and outcome of empyema in children in the north east of England. Thorax. 2004; 59:522-5. 
80. Von Kries $R$, Hermann $M$, Hachmeister $A$, Siedler A, Schmitt HJ, Al-Lahham A et al. Prediction of the potential benefit of different pneumococcal conjugate vaccines on invasive pneumococcal disease in German children. Pediatr Infect Dis J. 2002;21:1017-23.

81. Camou T, Palacio R, Di Fabio JL, Hortal M. Invasive pneumococcal diseases in Uruguayan children: comparison between serotype distribution and conjugate vaccine formulations. Vaccine. 2003;2093-6.

82. Kaltoft MS, Zeuthen N, Konradsen HB. Epidemiology of invasive pneumococcal infections in children aged 0-6 years in Denmark: a 19-year nationwide surveillance study. Acta Paediatr Suppl. 2000;89:3-10.

83. Brandileone MC, De Andrade AL, Di Fabio $J$, Guerra ML, Austrian R. Appropriateness of a pneumococcal conjugate vaccine in Brazil: potential impact of age and clinical diagnosis, with emphasis on meningitis. J Infect Dis. 2003;187:1206-12.

84. Hausdorff WP. Invasive pneumococcal disease in children: geographic and temporal variations in incidence and serotype distribution. Eur J Pediatr. 2002;161(Suppl.):S135-9.

85. Zissis NP, Syriopoulou V, Kafetzis D, Daikos GL, Tsilimingaki A, Galanakis E et al. Serotype distribution and antimicrobial susceptibility of Streptococcus pneumoniae causing invasive infections and acute otitis media in children. Eur J Pediatr. 2004;163:364-8.

86. Aguiar SI, Brito MJ, Gonçalo-Marques J, Melo-Cristino J, Ramirez M. Serotypes 1, 7F and 19A became the leading causes of pediatric invasive pneumococcal infections in Portugal after 7 years of heptavalent conjugate vaccine use. Vaccine. 2010;28:5167-73.

87. LuceroMG, Dulalia VE, Nillos LT, Williams G, Parreño RAN, Nohynek $\mathrm{H}$ et al. Pneumococcal conjugate vaccines for preventing vaccine-type invasive pneumococcal disease and $\mathrm{X}$-ray defined pneumonia in children less than two years of age. Cochrane Database of Systematic Reviews 2009, Issue 4. Art. No.: CD004977.

88. Jansen AGSC, Hak E, Veenhoven RH, Damoiseaux RAMJ, Schilder AGM, Sanders EAM. Pneumococcal conjugate vaccines for preventing otitis media. Cochrane Database of Systematic Reviews. 2009; Issue 2. Art. No.: CD001480.

89. Casey JR, Adlowitz DG, Pichichero ME. New patterns in the otopathogens causing acute otitis media six to eight years after introduction of pneumococcal conjugate vaccine. Pediatr Infect Dis J. 2010;29:304-9.

90. Millar EV, Watt JP, Bronsdon MA, Dallas J, Reid R, Santosham M et al. Indirect effect of 7-valent pneumococcal conjugate vaccine on pneumococcal colonization among unvaccinated household members. Clin Infect Dis. 2008;47:989-96.

91. Ardanuy C, Tubau F, Pallares R, Calatayud L, Domínguez MA, Rolo $D$ et al. Epidemiology of invasive pneumococcal disease among adult patients in Barcelona before and after pediatric 7-valent pneumococcal conjugate vaccine introduction, 1997-2007. Clin Infect Dis. 2009;48:57-64.

92. López B, Cima MD, Vázquez F, Fenoll $A$, Gutiérrez J, Fidalgo $C$ et al. Epidemiological study of Streptococcus pneumoniae carriers in healthy primary-school children. Eur J Clin Microbiol Infect Dis. 1999;18:771-6.

93. Rodrigues F, Nunes S, Sá-Leão R, Gonçalves $G$, Lemos L, de Lencastre $H$. Streptococcus pneumoniae nasopharyngeal carriage in children attending day-care centers in the central region of Portugal, in the era of 7-valent pneumococcal conjugate vaccine. Microb Drug Resist. 2009;15: 269-77.

94. Vestrheim DF, Høiby EA, Aaberge IS, Caugant DA. Impact of a pneumococcal conjugate 
vaccination program on carriage among children in Norway. Clin Vaccine Immunol. 2010;17:325-34.

95. Dunais $B$, Bruno $P$, Carsenti-Dellamonica $H_{1}$ Touboul P, Dellamonica P, Pradier C. Trends in nasopharyngeal carriage of Streptococcus pneumoniae among children attending daycare centers in southeastern France from 1999 to 2006. Pediatr Infect Dis J. 2008; 27:1033-5.

96. Grivea IN, Panagiotou M, Tsantouli AG, Syrogiannopoulos GA. Impact of heptavalent pneumococcal conjugate vaccine on nasopharyngeal carriage of penicillin-resistant Streptococcus pneumoniae among day-care center attendees in central Greece. Pediatr Infect Dis J. 2008;27:519-25.

97. O'Brien KL, Millar EV, Zell ER, Bronsdon $M_{1}$ Weatherholtz R, Reid R et al. Effect of pneumococcal conjugate vaccine on nasopharyngeal colonization among immunized and unimmunized children in a community-randomized trial. J Infect Dis. 2007; 196:1211-20.

98. Atienza Merino G. Evaluación económica de un programa de vacunación frente al neumococo en población pediátrica. Santiago de Compostela: Consellería de Sanidade, Axencia de Avaliación de Tecnoloxías Sanitarias de Galicia, avalia-t; 2010. Serie Avaliación de tecnoloxías. Consultas Técnicas; CT2010/03
99. Rozenbaum MH, Sanders EA, Van Hoek AJ, Jansen AG, Van der Ende A, Van den Dobbelsteen $G$ et al. Cost effectiveness of pneumococcal vaccination among Dutch infants: economic analysis of the seven valent pneumococcal conjugated vaccine and forecast for the 10 valent and 13 valent vaccines. BMJ. 2010;340:c2509.

100. Beall B. Vaccination with the pneumococcal 7-valent conjugate: a successful experiment but the species is adapting. Expert Rev Vaccines. 2007;6:297-300

101. Hanage WP, Huang SS, Lipsitch M, Bishop CJ, Godoy D, Pelton SI et al. Diversity and antibiotic resistance among nonvaccine serotypes of Streptococcus pneumoniae carriage isolates in the post-heptavalent conjugate vaccine era. J Infect Dis. 2007;195:347-52.

102. Prymula R, Kriz P, Kaliskova E, Pascal T, Poolman J, Schuerman L. Effect of vaccination with pneumococcal capsular polysaccharides conjugated to Haemophilus influenzae-derived protein D on nasopharyngeal carriage of Streptococcus pneumoniae and $\mathrm{H}$. influenzae in children under 2 years of age. Vaccine. 2009;28:71-8

103. Tai SS. Streptococcus pneumoniae protein vaccine candidates: properties, activities and animal studies. Crit Rev Microbiol. 2006;32:139-53. 